\title{
A RARE PRESENTATION OF CEREBROVASCULAR INSUFFICIENCY
}

\author{
Chikkalingaiah ${ }^{1}$, Dhivya $\mathrm{P}^{2}$, Keshava $\mathrm{H}^{3}$
}

\section{HOW TO CITE THIS ARTICLE:}

Chikkalingaiah, Dhivya P, Keshava H. "A Rare Presentation of Cerebrovascular Insufficiency". Journal of Evolution of Medical and Dental Sciences 2015; Vol. 4, Issue 13, February 12; Page: 2235-2238,

DOI: $10.14260 /$ jemds/2015/323

ABSTRACT: Locked in syndrome refers to a neurological condition associated with infarction of the ventral pons. The syndrome is manifested by quadriplegia, lower cranial nerve paralysis and mutism with preservation of only vertical gaze and upper eyelid movement. The aetiology is multifactorial, with the lesion usually in the ventral pons. The "locked-in" patient is literally locked inside his body, aware of his environment but with a severely limited ability to interact with it. We present this case report to highlight and create awareness about this clinical entity. CONCLUSION: Locked in state is one of the important differential diagnosis for vegetative state. It is relatively rare and is important to recognise the same as the prognosis for the patient is poor.

KEYWORDS: Coma, locked in state, quadriplegia.

CASE REPORT: A 65 year old male patient was brought to the casualty in the evening with history of loss of consciousness. Patient had one episode of vomiting in the morning following breakfast. 6 hours prior to presentation at our hospital, he was resting in a chair when the patient attenders noticed sudden onset of loss of consciousness characterised by fall from the chair and they noticed weakness of all four limbs during the time. There was no history of convulsion or headache. He was a known case of hypertension since 2 years and was on irregular medication. There was no previous history of TIA or seizures.

On examination, his blood pressure was $160 / 90 \mathrm{mmHg}$ with regular pulse rate and oxygen saturation. His breathing pattern was normal. Patient had a GCS of E2V1M1. Response to oral commands and painful stimuli was in the form of eye opening and eye blinking. Pupils were bilaterally pin point. There was flaccid quadriplegia. Plantars were bilaterally mute. Sensory system could not be assessed. His Random Blood sugar on admission was normal. ECG showed sinus tachycardia. 2D Echo showed concentric left ventricular hypertrophy with an ejection fraction of $65 \%$. Patient was sent for CT Brain which was normal.

Since there was no improvement in his consciousness level, after 3 hours a repeat CT scan was done which showed hypo densities in left cerebellum and left pons suggestive of an evolving infarction to posterior circulation. Patient was electively intubated and connected to ventilator in anticipation of respiratory distress. A presumptive diagnosis of a locked in state was made secondary to a vascular event and he was also started on anti-platelet drugs for stroke management along with physiotherapy.

Patient was gradually weaned from ventilator over a period of one week. During this period patient continued to respond to commands with eye blinking and eye opening indicative that he was aware of his surroundings with intact vision and hearing. Communication in the form of yes and no was started depending on number of eye blinks. After patient was completely weaned from ventilator an MRI Brain was done which showed multifocal subacute infarct with haemorrhagic transformation in bilateral cerebellar hemisphere, pons and bilateral thalamus suggestive of a locked in state and thus confirming our diagnosis. 


\section{CASE REPORT}

During the course of hospitalisation, patient then developed irregular breathing pattern with hypoxia and hence had to be reconnected to ventilator. Eventually the patient died 15 days later due to respiratory failure.

DISCUSSION: The first description of locked-in syndrome was probably in 1868. In Thérèse Raquin, Emile Zola wrote that one of his characters "could communicate quite easily with that imprisoned mind buried alive in a dead body". The term locked-in syndrome is attributed to Plum and Posner, who described a 44-yr-old man with complete occlusion of the basilar artery. The prevalence is unknown as there is no good data regarding the incidence and prevalence but locked in syndrome is a very rare condition. The cardinal signs of LIS include tetraplegia, lower cranial nerve palsy, and anarthria, with preserved consciousness. Three varieties of "locked-in syndrome," which are termed Classical, Incomplete, and Total, were proposed by Bauer in 1979.

The Classical variety is composed of patients with the signs and symptoms of "locked-in syndrome" as originally described by Plum and Posner. The Incomplete category is similar to the Classical variety except that the patients have remnants of voluntary motion besides upper eyelid and vertical eye movement. The Total variety is composed of a group of patients who are totally immobile, and are unable to communicate. These patients are aware of both internal and external stimuli but are able to carry on only an internal monologue. Bauer further divided each variety into transient and chronic forms.

Locked-in syndrome is usually caused by pontine infarction after prolonged vertebrobasilar ischaemia. Other causes include haemorrhage, tumour, trauma, central pontine myelinolysis, pontine abscess, interscalene brachial plexus blocks and postinfective polyneuropathy. Cerebral air embolism and transient vertebrobasilar insufficiency are potentially reversible causes. The site of the lesion is usually in the basis pontis and there may be variable involvement of the pontine tegmentum, medulla and midbrain. Preservation of voluntary eye movements occurs when the lesion remains caudal to the nucleus of the occulomotor nerve; consciousness is preserved when the reticular formation in the dorsal pons is unaffected by the lesion.

The diagnosis can be made clinically. The prognosis after ventral pontine infarction is often fatal from respiratory failure or extension of the infarct. Recovery can occur from the locked-in syndrome, but most survivors remain in a chronic locked-in state or are severely impaired. Significant recovery may occur when the duration of the syndrome is less than $24 \mathrm{~h}$, usually after a transient ischaemic attack. In a case review published by Patterson and Gabrois, reported mortality was $60 \%$. Overall, the prognosis for survival and recovery was found to be better in the group of patients whose syndrome was nonvascular in origin than those with a vascular etiology. Functional recovery was generally good in those patients with a vascular etiology who survived beyond 4 months while recovery occurred earlier and more completely in the nonvascular group. Thus, a program of intensive rehabilitation should be considered early in both groups in order to assist each patient in attaining the highest level of function possible as recovery progresses.

Accurate diagnosis of LIS in the early stages is critical for establishing a prognosis and appropriate management strategies. However, patients with LIS might initially be comatose, which can delay the diagnosis. Injury to tegmental regions of the upper pons and midbrain increases the likelihood of initial disturbances in consciousness, but CT scans completed in the acute stage of injury are limited in their capacity to detect edema or regional infarction in these brain structures. 
In our patient initial CT done was normal but continued loss of consciousness led us to repeat the CT which after 3 hours showed evidence of infarction.

CONCLUSION: In a locked in state because they are alert, it is important to establish a consistent form of communication to be used with the patient. The "locked-in" patient is at a high risk of developing significant respiratory problems. These patients should be monitored closely for any evidence reflecting a need for ventilatory assistance, a reduced ability to handle their secretions or early signs of a respiratory infection.

When respiratory problems develop, early intervention should be considered including respiratory assistance when indicated. Finally, as a preventive measure these patients should be started in a program of pulmonary hygiene that should be continued after discharge from the hospital, especially during the initial 4-6 months following onset. The case is presented to highlight the importance of recognizing this entity and prevent the misdiagnosis of a vegetative state.

\section{BIBLIOGRAPHY:}

1. Plum F, Posner JB: The Diagnosis of Stupor and Coma. Philadelphia, Davis, 1966.

2. Patterson JR, Grabois Martin. Locked - In Syndrome: A Review Of 139 Cases. Stroke 1986; 17(4): 758-64.

3. Casanova E, Lazzari RE, Lotta S, Mazzucchi A. Locked-in syndrome: improvement in the prognosis after an early intensive multidisciplinary rehabilitation. Arch Phys Med Rehabil 2003; 84(6): 862-67.

4. Leon - Carrion J, Van Eeckhout P, Dominguez - Morales Mdel R, Perez - Santamaria FJ. The locked -in syndrome: a syndrome looking for a therapy. Brain Inj. 2002 Ju l; 16(7): 571-82.

5. Smith E, Delargy M. Locked-in syndrome BMJ 2005; 330: 406-409.

6. Bauer G, Gerstenbrand F, Rumpl E. Variables of the locked- in syndrome. J Neurol 1979; 221: 77-91.

7. Breen P, Hannon V. Locked - In Syndrome: a catastrophic complication after surgery. Br J Anaesth 2004; 92(2); 286-8.

8. Cherington M, Stears J, Hodges J. Locked-in syndrome caused by a tumour. Neurology 1976; 26: $180-2$.

9. Fox C, Lavin M. Vertebral artery dissection resulting in locked-in syndrome. Neurosci Nurs 1991; 23: 287-9.

10. Budak F, Ilhan A, Ozmenoglu M, Komsuoglu S. Locked-In Syndrome: A Case Report. Clinical EEG and Neuroscience. 1994; 25 (1): 40-43. 


\section{CASE REPORT}

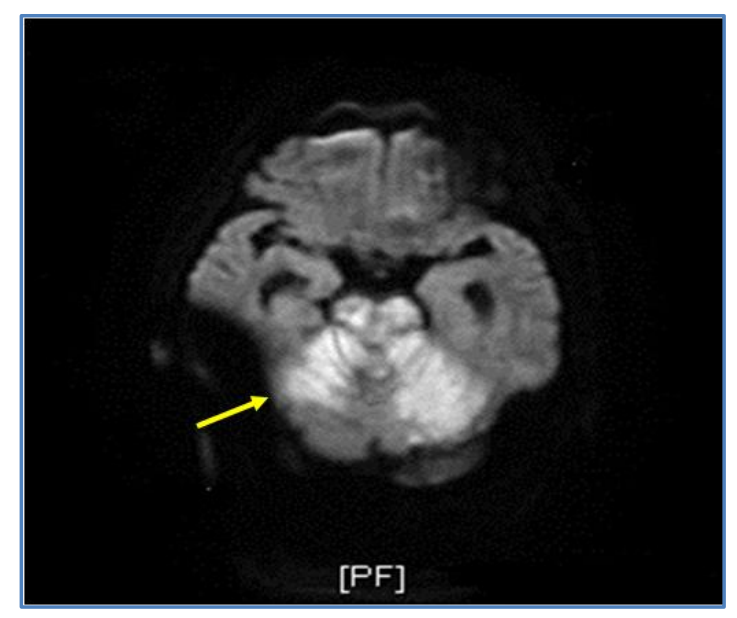

Fig. 1: DWI showing bilateral cerebellar infarction

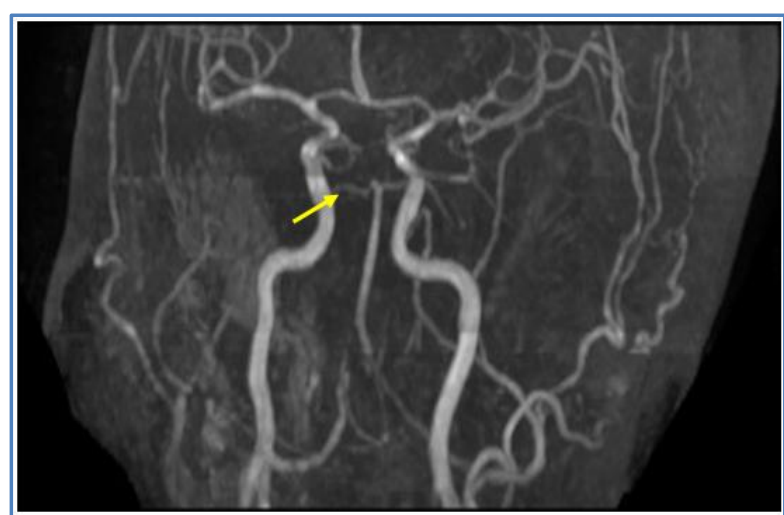

Fig. 2: MR Angiogram showing Right Vertebral Artery

\section{AUTHORS:}

1. Chikkalingaiah

2. Dhivya P.

3. Keshava $\mathrm{H}$.

\section{PARTICULARS OF CONTRIBUTORS:}

1. Professor, Department of Medicine, KIMS, Bangalore.

2. Resident, Department of Medicine, KIMS, Bangalore.

3. Associate Professor, Department of Medicine, KIMS, Bangalore.

\section{FINANCIAL OR OTHER}

COMPETING INTERESTS: None

\section{NAME ADDRESS EMAIL ID OF THE} CORRESPONDING AUTHOR:

Dr. Dhivya $P$,

SF-1, RK Mansion,

$4^{\text {th }}$ Cross, $7^{\text {th }}$ Main,

Syndicate Bank Colony,

Banashankari 3rd Stage,

Bangalore-560085.

E-mail: drpdhivya11@gmail.com

Date of Submission: 18/01/2015.

Date of Peer Review: 19/01/2015.

Date of Acceptance: 05/02/2015.

Date of Publishing: 12/02/2015. 